\title{
Monitoring changes of the Antarctic Ice sheet by GRACE, ICESat and GNSS
}

\author{
Fang ZOU, Robert TENZER*, Samurdhika RATHNAYAKE \\ Department of Land Surveying and Geo-Informatics, Hong Kong Polytechnic University, \\ 181 Chatham Road South, Kowloon, Hong Kong
}

\begin{abstract}
In this study, we estimate the ice mass changes, the ice elevation changes and the vertical displacements in Antarctica based on analysis of multi-geodetic datasets that involve the satellite gravimetry (GRACE), the satellite altimetry (ICESat) and the global navigation satellite systems (GNSS). According to our estimates, the total mass change of the Antarctic ice sheet from GRACE data is $-162.91 \mathrm{Gt} / \mathrm{yr}$ over the investigated period between April 2002 and June 2017. This value was obtained after applying the GIA correction of $-98.12 \mathrm{Gt} / \mathrm{yr}$ derived from the ICE-5G model of the glacial isostatic adjustment. A more detailed analysis of mass balance changes for three individual drainage regions in Antarctica reveal that the mass loss of the West Antarctic ice sheet was at a rate of $-143.11 \mathrm{Gt} / \mathrm{yr}$. The mass loss of the Antarctic Peninsula ice sheet was at a rate of $-24.31 \mathrm{Gt} / \mathrm{yr}$. The mass of the East Antarctic ice sheet increased at a rate of $5.29 \mathrm{Gt} / \mathrm{yr}$ during the investigated period. When integrated over the entire Antarctic ice sheet, average rates of ice elevation changes over the period from March 2003 to October 2009 derived from ICESat data represent the loss of total ice volume of $-155.6 \mathrm{~km}^{3}$. The most prominent features in ice volume changes in Antarctica are characterized by a strong dynamic thinning and ice mass loss in the Amundsen Sea Embayment that is part of the West Antarctic ice sheet. In contrast, coastal regions between Dronning Maud Land and Enderby Land exhibit a minor ice increase, while a minor ice mass loss is observed in Wilkes Land. The vertical load displacement rates estimated from GRACE and GPS data relatively closely agree with the GIA model derived based on the ice-load history and the viscosity profile. For most sites, the GRACE signal appears to be in phase and has the same amplitude as that obtained from the GPS vertical motions while other sites exhibit some substantial differences possibly attributed to thermo-elastic deformations associated with surface temperature.
\end{abstract}

Key words: Antarctica, ice sheet, glacier, GRACE, ICESat

\section{Introduction}

The Antarctic ice sheets, the world's largest single mass of ice, cover an area of $14 \times 10^{6} \mathrm{~km}^{2}$. The knowledge and understanding of the mass balance of

\footnotetext{
*corresponding author: phone: +852 2766-5592; email: robert.tenzer@polyu.edu.hk
} 
this vaste ice volume play a key role in studies of global sea level change and global water cycle (e.g. Tang et al., 2012; Shepherd and Wingham, 200\%; or Jacob et al., 2012). Antarctic glaciers also provide important information about the past and present climate that could help understanding the impact of future climate change (e.g. Zammit-Mangion et al., 2015; Van Wessem et al., 2014; or Hanna et al., 2013).

The mass balance of the Antarctic ice sheet has long been a controversial topic, because of difficulties in estimating it accurately. This is evident from Table 1, where we summarized estimates of the total mass balance of the Antarctic ice sheet from selected studies. As seen, the results from different or even the same techniques (i.e. satellite-radar altimetry, satellite gravity, or Synthetic Aperture Radar) differ significantly. The results from the satellite radar altimetry, such as ICESat, suggest a mass rate for the whole continent in the range from -89 to $-103 \mathrm{Gt} / \mathrm{yr}$ for the period 2003-2007. Spatial variations in snow, firn ice and ice densities and thickness have a significant impact on the final mass change estimates. Consequently, it makes it difficult to assess realistically uncertainties of the ICESat estimates. Results from the Interferometric Synthetic Aperture Radar (InSAR) indicate that over the last decade, the glacial mass discharge exceeds model predictions of the snow accumulation. Based on the analysis of ERS-1 and ERS-2 data, Zwally et al. (2005) suggested that the mass loss of the Antarctic ice sheet was at a rate of $-31 \pm 12 \mathrm{Gt} / \mathrm{yr}$ within the period from 1992 to 2002 . The estimates of Antarctic ice/snow mass changes from monitoring the ice elevation changes (based on radar altimetry and radar scatter meter) are limited by spatial and temporal coverage and by uncertainties in snow and firn ice density and thickness. Estimates of mass changes of the Antarctic ice sheet from the Gravity Recovery And Climate Experiment (GRACE) range from -60 up to about $-190 \mathrm{Gt} / \mathrm{yr}$ (cf. Table 1). These large discrepancies in published results are mainly due to different methods used to convert the monthly gravity field solutions (expressed as spherical harmonics, i.e. Level-2 GRACE data) into surface mass changes. Major reasons are related to processing GRACE data from different data centres, using different processing methods that involve filtering techniques, treatments of low-degree terms and the leakage of GRACE signals between different mass bodies. Important aspect is also due to uncertainties associated with other geophysical signals in GRACE data, particularly to mention the Glacial 
Isostatic Adjustment (GIA). Naturally, differences in published results are also due to processing of GRACE data over different time-periods. Velicogna and Wahr (2006), for instance, estimated that over the first three years of GRACE data availability between April 2002 and August 2005, the total mass loss of the Antarctic ice sheet was at a rate of $-152 \pm 80 \mathrm{Gt} / \mathrm{yr}$ (while accounting for the GIA correction of $192 \pm 79 \mathrm{Gt} / \mathrm{yr}$ ). This ice mass loss is equivalent to a global sea level rise at a rate of $0.4 \pm 0.2 \mathrm{~mm} / \mathrm{yr}$. Chen et al. (2009), based on the analysis of GRACE RL04 data products, estimated the total mass loss of the Antarctic ice sheet at a rate of $-190 \pm 77 \mathrm{Gt} / \mathrm{yr}$ during the period between April 2002 and January 2009. Ivins et al. (2013) demonstrated that uncertainties in GIA largely affect estimates of the total

Table 1. Major studies of the total mass balance of the Antarctic ice sheet.

\begin{tabular}{|c|c|c|c|c|c|c|c|}
\hline Study & Data & Time span & Filtering & GIA model & $\begin{array}{c}\text { Leakage } \\
\text { effect }\end{array}$ & $\begin{array}{c}\text { Rate } \\
{[\mathbf{G t} / \mathbf{y r}]}\end{array}$ & $\begin{array}{c}\text { Acceleration } \\
{\left[\mathbf{G t} / \mathbf{y r}^{\mathbf{2}}\right]}\end{array}$ \\
\hline $\begin{array}{l}\text { Zwally et al. } \\
\text { (2005) }\end{array}$ & ERS & $1992-2002$ & & & & \multicolumn{2}{|c|}{$-31 \pm 12$} \\
\hline $\begin{array}{l}\text { Velicogna et } \\
\text { al. }(2006)\end{array}$ & $\begin{array}{l}\text { GRACE } \\
\text { RL04 }\end{array}$ & $2002.4-2005.8$ & & $\begin{array}{c}\text { ICE5G } \\
192 \pm 79 \mathrm{Gt} / \mathrm{y}\end{array}$ & GLDAS & $152 \pm 80$ & \\
\hline $\begin{array}{l}\text { Chen et al. } \\
\text { (2006) }\end{array}$ & $\begin{array}{l}\text { GRACE } \\
\text { RL04 }\end{array}$ & $2002.04-2005.11$ & $\begin{array}{l}800 \mathrm{~km} \\
\text { Gausian }\end{array}$ & $\begin{array}{l}\text { No GIA } \\
\text { correction }\end{array}$ & $\begin{array}{c}\text { Numerical } \\
\text { Simulation } \\
\text { IJ05 }\end{array}$ & \multicolumn{2}{|c|}{$-31 \pm 12$} \\
\hline \multirow[t]{2}{*}{$\begin{array}{l}\text { Gunter et al. } \\
\text { (2009) }\end{array}$} & $\begin{array}{l}\text { GRACE } \\
\text { RL04 }\end{array}$ & $2003.02-2007.02$ & $\begin{array}{c}\text { Kaula } \\
\text { regularization, } \\
\text { P3M7 and } \\
400 \mathrm{~km} \\
\text { Gaussian }\end{array}$ & $\begin{array}{c}\text { ICE5G } \\
149 \mathrm{Gt} / \mathrm{y}\end{array}$ & $\begin{array}{l}\text { Klees et al. } \\
\quad \text { (2008) }\end{array}$ & -91 to -102 & \\
\hline & ICESat & $2003.02-2007.02$ & & $\begin{array}{c}\text { IJ05 } \\
107 \mathrm{Gt} / \mathrm{y}\end{array}$ & & -89 to -103 & \\
\hline $\begin{array}{l}\text { Chen et al. } \\
\text { (2009) }\end{array}$ & $\begin{array}{l}\text { GRACE } \\
\text { RL04 }\end{array}$ & $2002.04-2009.01$ & $\begin{array}{l}\text { P4M6 and } \\
300 \mathrm{~km} \\
\text { Gaussian }\end{array}$ & IJ05 & $\begin{array}{l}\text { forward } \\
\text { modelling }\end{array}$ & $-190 \pm 77$ & \\
\hline $\begin{array}{l}\text { Velicogna } \\
\text { (2009) }\end{array}$ & CSR & $2002.04-2009.02$ & $\begin{array}{l}\text { a specific } \\
\text { factor }\end{array}$ & $176 \pm 76 \mathrm{Gt} / \mathrm{y}$ & $\begin{array}{l}\text { Wahr et al. } \\
\text { (2006) }\end{array}$ & -246 & $-26 \pm 14$ \\
\hline $\begin{array}{l}\text { Jacob et al. } \\
\text { (2012) }\end{array}$ & CSR RL05 & $2003.01-2010.12$ & $\begin{array}{c}\text { averaging } \\
\text { kernel }\end{array}$ & ICE5G & $\mathrm{N}$ & $-165 \pm 72$ & \\
\hline $\begin{array}{l}\text { Chen et al. } \\
\text { (2009) }\end{array}$ & $\begin{array}{l}\text { GRACE } \\
\text { RL04 }\end{array}$ & $2002.04-2009.01$ & $\begin{array}{l}\text { P4M6 and } \\
300 \mathrm{~km} \\
\text { Gaussian }\end{array}$ & IJ05 & $\begin{array}{l}\text { forward } \\
\text { modelling }\end{array}$ & $-190 \pm 77$ & \\
\hline \multirow{3}{*}{$\begin{array}{l}\text { Ivins et al. } \\
\text { (2013) }\end{array}$} & \multirow{3}{*}{$\begin{array}{l}\text { GRACE } \\
\text { RL05 }\end{array}$} & \multirow{3}{*}{$2003.02-2013.06$} & \multirow{3}{*}{$\begin{array}{c}3^{\circ} \text { Gaussian } \\
\text { smoothing } \\
\text { operator }\end{array}$} & ICE5G & & $-171 \pm 22$ & $-12 \pm 7$ \\
\hline & & & & IJ05 R2 & & $-93 \pm 29$ & $-12 \pm 7$ \\
\hline & & & & W12a & & $-91 \pm 23$ & $-12 \pm 7$ \\
\hline $\begin{array}{l}\text { Velicogna et } \\
\text { al. (2014) }\end{array}$ & $\begin{array}{l}\text { GRACE } \\
\text { RL05 }\end{array}$ & 2003.01-2013.12 & $\begin{array}{c}250 \mathrm{~km} \\
\text { Gaussian }\end{array}$ & $\begin{array}{l}\text { Ivins et al. } \\
\text { (2013) and } \\
\text { ICEG5G }\end{array}$ & $\begin{array}{l}\text { Velicogna and } \\
\text { Wahr (2013) }\end{array}$ & $-67 \pm 44$ & $-11 \pm 4$ \\
\hline This study & $\begin{array}{c}\text { GRACE } \\
\text { CSR RL06 }\end{array}$ & $2002.04-2017.06$ & $\begin{array}{l}\text { P4M6 and } \\
500 \mathrm{~km} \\
\text { Gaussian }\end{array}$ & ICE5G & $\begin{array}{l}\text { forward } \\
\text { method }\end{array}$ & $-162.91 \pm 5.09$ & $-10.12 \pm 4.3$ \\
\hline
\end{tabular}


mass balance in Antarctica. For the investigated period between February 2003 and June 2013, they reported rates of the mass loss from -91 to $-171 \mathrm{Gt} / \mathrm{yr}$. In more recent study, Velicogna et al. (2014) estimated that over the period between January 2003 and December 2013 the mass loss was at a rate of only $-67 \pm 44 \mathrm{Gt} / \mathrm{yr}$.

In this study, we estimated the total mass changes over the entire continent of Antarctica using GRACE data. We also provided individual estimates for three major Antarctic regions, involving the East and West Antarctica and the Antarctic Peninsula. We estimated ice elevations and their changes based on the analysis of ICESat data. We then compared results obtained from GRACE and ICESat data, focusing on secular trends observed in the ice elevation and mass variability. These secular trends were validated using vertical displacements from the continuous GPS stations installed in Antarctica.

\section{Data acquisition}

In this section, we briefly describe datasets and models used to estimate changes of the total mass budget in Antarctica.

\subsection{Study area}

Applying a commonly adopted geographical description of Antarctica, we investigated the mass balance for the whole continent as well as for three distinctive regions (see Fig. 1). West and East Antarctica are separated by the Transantarctic Mountains spreading between the Ross Sea and the Weddell Sea. West Antarctica is covered by the West Antarctic ice sheet. The ice sheet has been of recent concern because of a possibility of its collapse. East Antarctica lies on the Indian Ocean side of the Transantarctic Mountains. Only small portion of East Antarctica is part of the western hemisphere. East Antarctica is largely covered by the East Antarctic ice sheet. The Antarctic Peninsula is part of a larger peninsula of West Antarctica. The Antarctic Peninsula consists of a string of bedrock islands beneath the ice sheet, which cover it. Floating ice shelves whose mass GRACE does not measure are not discussed in this paper. 


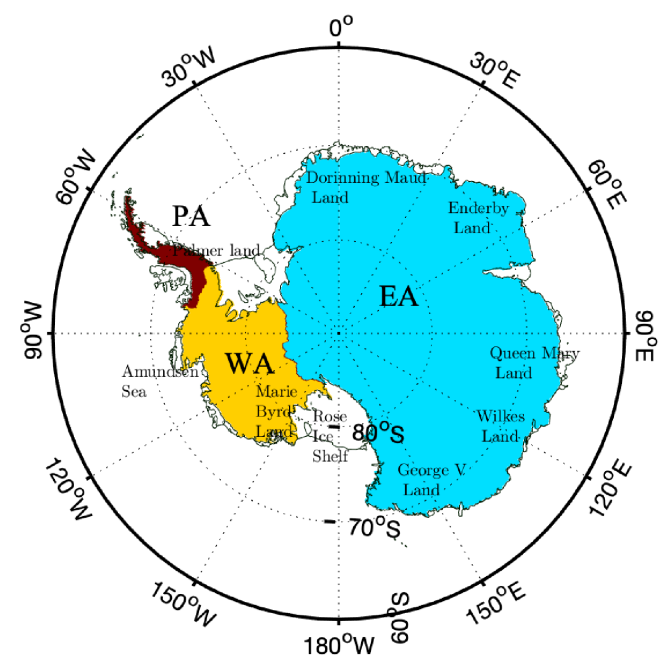

Fig. 1. The Antarctic drainage system, comprising the West Antarctic (WA) ice sheet, the East Antarctic (EA) ice sheet, and the Antarctic Peninsula (PA) ice sheet.

\subsection{GRACE data}

We used the GRACE RL06 monthly solutions prepared by the Center for Space Research at the University of Texas at Austin over the period from April 2002 to June 2017. The GRACE monthly solutions are provided with the spectral resolution up to degree of 60 . The first-degree spherical harmonic coefficients that could not directly be detected by GRACE were determined from combining GRACE data with numerical ocean models. The second-zonal spherical harmonic coefficient $\mathrm{C}_{20}$ (due to Earth's flattening) was determined from the analysis of the Satellite Laser Ranging measurements. The P4M6 decorrelation filter was applied for destripping. The Gaussian filter (with a radius of $500 \mathrm{~km}$ ) was applied to minimize spatial noise in GRACE monthly solutions. We note that monthly variations were taken with respect to the average value over the entire period (from April 2002 to June 2017).

\subsection{ICESat data}

We used the ICESat/GLAS Level 2 altimetry product (GLA14) that includes the global land surface elevation data, the footprint centroid ge- 
olocation, the laser reflectance, the geoid, the instrument gain, the waveform saturation and many other relevant parameters. The ICESat/GLA14 Release-34 elevation data crossing Antarctica over the period from March 2003 to October 2009 were obtained through the National Snow and Ice Data Center (NSIDC). The ICESat ground tracks over this period are illustrated in Fig. 2.



Fig. 2. The ICESat ground tracks in Antarctica over the period from March 2003 to October 2009.

\subsection{Glacial isostatic adjustment}

GIA models depend on the hypotheses on the ice-load history and the viscosity profile. In this study, we adopted the recent GIA model to correct for secular mass changes derived from GRACE data based on the ICE5G iceload history, the VM2 viscosity profile and the same PREM elastic structure (A et al., 2013).

\section{Method}

Data and models described in the preceding section were used to estimate changes in total mass balance and elevations of the Antarctic ice sheet according to methods briefly recapitulated next. 


\subsection{Water storage change from GRACE}

The monthly GRACE solutions consist of the (fully-normalized) spherical harmonic coefficients $\Delta C_{n m}$ and $\Delta S_{n m}$ of degree $n$ and order $m$. The terrestrial water storage anomalies $\Delta \eta$ over the land were computed directly from these coefficients for a particular time period $t$ (typically choosing a monthly period) according to the following expression (e.g. Wahr et al., 1998):

$$
\begin{aligned}
\Delta \eta(\theta, \lambda, t)=\frac{R \rho}{3 \rho_{w}} \sum_{n=0}^{\infty} & \sum_{m=0}^{n} \frac{2 n+1}{\left(1+k_{n}^{\prime}\right)} W_{n} \tilde{P}_{n m}(\cos \theta) \times \\
& \times\left(\Delta \hat{C}_{n m}(t) \cos m \lambda+\Delta \hat{S}_{n m}(t) \sin m \lambda\right),
\end{aligned}
$$

where $\rho$ is Earth's mean density, $\rho_{w}$ is the freshwater density, $R$ is Earth's equatorial radius, $\tilde{P}_{n m}(\cos \theta)$ represents the (fully-normalized) Legendre associated function of degree $n$ and order $m, k_{n}^{\prime}$ represents the (degreedependent) Love number, $n=60$ is a maximum degree of spherical harmonics, and $W_{n}$ is the (degree-dependent) kernel function of a Gaussian filter. The horizontal position in Eq. (1) and thereafter is described by the spherical co-latitude $\theta$ and longitude $\lambda$.

GRACE data has a limited spatial resolution. Moreover, the GRACE monthly solutions are spatially filtered in order to reduce the noise. Therefore, a leakage effect suppresses the actual gravitational signal attributed to ice sheet mass variations. This effect causes inaccurate results, particularly in land-ocean areas. It significantly attenuates amplitudes and biases of mass balance estimates in Antarctica. We applied forward modelling technique to estimate monthly solutions of the GRACE mass variations in order to mitigate the ocean-land signal leakage.

By taking into consideration annual and semi-annual signals, the longterm change rate was estimated by applying an ordinary least-square fit at each grid point. This numerical procedure is described by means of secular and seasonal trends of monthly mass anomalies in the following form:

$$
\begin{aligned}
M(\theta, \lambda)=a_{1}+a_{2}\left(t-t_{0}\right)+ & a_{3} \sin \left[w_{1}\left(t-t_{0}\right)+\varphi_{1}\right]+ \\
& +a_{4} \sin \left[w_{2}\left(t-t_{0}\right)+\varphi_{2}\right]+\varepsilon,
\end{aligned}
$$

where $M$ is the surface mass anomaly specified at a location $(\theta, \lambda), t_{0}$ is an initial epoch (in this study August 2002), $a_{2}$ is a linear rate of mass 
changes at a grid point $(\theta, \lambda), a_{3}$ and $a_{4}$ are amplitudes of annual $w_{1}$ and semi-annual $w_{2}$ frequencies, respectively, $\varphi_{1}$ and $\varphi_{2}$ are phases, and $\varepsilon$ is the noise. The surface mass anomaly described by a functional model in Eq. (2) comprises the GIA secular trend and the secular as well as seasonal trends in mass balance variations.

To estimate the surface displacement due to the mass load effect, we used the CSR de-aliasing Level-1B (AOD1B) solution (GAC products) and the monthly Stokes' coefficients GSM (GRACE satellite only model) to compute the whole surface vertical loads, including the hydrological, atmospheric and non-tidal ocean loads. The vertical displacement $\mathrm{d} r$ due to the changing mass load is defined in terms of spherical harmonic coefficients for gravity field from GRACE (including GSM and GAC productions). It reads (Farrell, 1972):

$$
\begin{aligned}
\mathrm{d} r(\theta, \lambda)=R \sum_{n=0}^{\infty} \sum_{m=0}^{n} \frac{h_{n}^{\prime}}{\left(1+k_{n}^{\prime}\right)} \tilde{P}_{n m}(\cos \theta) \times \\
\quad \times\left(\Delta \hat{C}_{n m}(t) \cos m \lambda+\Delta \hat{S}_{n m}(t) \sin m \lambda\right),
\end{aligned}
$$

where $h_{n}^{\prime}$ and $k_{n}^{\prime}$ are the (degree-dependent) Love numbers.

\subsection{Elevation changes from ICESat}

The GLA14 data release is provided with control indicators and corrections to illustrate data acquisition and to correct elevation data. In order to ensure data accuracy and to improve data quality, we selected the ICESat elevation data based on checking a quality index and applying a number of necessary corrections (such as the saturation elevation correction).

We used planes fitted to the repeated-tracks method to measure elevation changes. Firstly, we applied least-square regression technique that fits rectangular planes to segments of the repeated-track ICESat data. Along each reference track, multi-temporal ICESat points were assigned to $700 \mathrm{~m}$ long planes, with overlaps of $350 \mathrm{~m}$. The width of planes depends on the maximum cross-track separation distance between repeated profiles, typically a few hundred meters. The plane equation describes the change of plane elevation and gradient in different periods as follows:

$h(t, x, y)=S_{e}\left(x-x_{0}\right)+S_{n}\left(y-y_{0}\right)+\mathrm{d} h / \mathrm{d} t v\left(t-t_{0}\right)+h_{0}$, 
where $x$ and $y$ are coordinates and $t$ is the observation time of each observation point on a plane; $h$ is the elevation of each observation point on the plane; $x_{0}$ and $y_{0}$ are coordinates of a central reference point on a plane; $h_{0}$ is the elevation of a central reference point on a plane; and $t_{0}$ is a reference time.

For each plane, the east and north slopes $S_{e}$ and $S_{n}$ including the constant elevation change rate $\mathrm{d} h / \mathrm{d} t$ were estimated by solving the following system of observation equations:

$$
\left[\begin{array}{c}
\mathrm{d} h_{1} \\
\mathrm{~d} h_{2} \\
\vdots \\
\mathrm{d} h_{n}
\end{array}\right]=\left[\begin{array}{ccc}
\mathrm{d} x_{1} & \mathrm{~d} y_{1} & \mathrm{~d} t_{1} \\
\mathrm{~d} x_{2} & \mathrm{~d} y_{2} & \mathrm{~d} t_{2} \\
\vdots & \vdots & \vdots \\
\mathrm{d} x_{n} & \mathrm{~d} y_{n} & \mathrm{~d} t_{n}
\end{array}\right]\left[\begin{array}{c}
S_{e} \\
S_{n} \\
\mathrm{~d} h / \mathrm{d} t
\end{array}\right]+\left[\begin{array}{c}
r_{1} \\
r_{2} \\
\vdots \\
r_{n}
\end{array}\right],
$$

where $\mathrm{d} x, \mathrm{~d} y, \mathrm{~d} h$ and $\mathrm{d} t$ are, respectively, differences in the 3 -D position $(x, y, h)$ and time $t$ (in decimal years) between each point and the average of all points on a plane. The residuals $r$ of a plane regression contain remaining elevation variations, which cannot be attributed to an assumption of planar slopes and an invariable elevation change rate. To avoid gross errors in $\mathrm{d} h / \mathrm{d} t$ due to cloud-affected signals or a small-scale topography, we removed potential outlier points if $r>5 \mathrm{~m}$ and recomputed the regression iteratively until all residuals were below this threshold. We removed all planes with a shorter observational time span than two years and planes that consisted of less than four repeated tracks or less than 10 points. It is also noted that we used filter to make sure that each plane coincided with the same season (such as winter-to-winter) to reduce the impact of seasonal bias.

\section{Results and analysis}

Methods recapitulated in Section 3 were applied to estimate changes in total mass budget of the Antarctic ice sheet from GRACE data after applying the GIA correction. We also used ICESat data to estimate elevation changes of the Antarctic ice sheet. The results are presented in this section.

\subsection{Mass changes from GRACE}

Without considering uncertainties, the time series of ice sheet mass changes 
estimated from GRACE data include the long-term (secular), seasonal and inter-annual signals. The long-term signal mainly reflects the trend of mass changes of the ice sheet over the period of cyclical fluctuations exceeding more than 10 years. The long-term signal is used to evaluate the state of ice sheet mass balance. Seasonal signals are seasonal or short-term fluctuations in the mass change of ice sheets caused by seasonal factors such as Earth's revolution around the Sun. The seasonal signals are dominated by annual and semi-annual changes. The inter-annual signal is the mass change signal whose spectrum is between the seasonal and long-term signals, which is often greater than 1 year and less than 10 years. It mainly reflects variations in the ice sheet mass during the years. Taking into account seasonal and inter-annual changes, we derived the long-term changes of the Antarctic ice sheet mass from GRACE data. Results are presented in Fig. 3.

Maps of secular mass change rate indicate that the West Antarctic ice sheet and Antarctica Peninsula experienced a significant ice loss over the fifteen-year period. Coastal areas in the East Antarctic ice sheet $\left(30^{\circ} \mathrm{W} \sim\right.$ $65^{\circ} \mathrm{E}$ ), on the other hand, experienced a slight mass accumulation. As seen in Fig. 3, the leakage effect attenuates the amplitude of mass change signal, especially in areas where the significant mass loss occurred. Before the leakage effect correction, the mass loss of Marie Byrd Land, which is part of the West Antarctic ice sheet, was the fastest reaching -5 to $-10 \mathrm{~cm} / \mathrm{yr}$ (cf. Fig. 3a). After applying the leakage correction, the mass loss there was estimated to be at a rate up to $-20 \mathrm{~cm} / \mathrm{yr}$. We see that after applying this correction, most of the mass change signal in Antarctica was restored. The mass loss rate of the West Antarctic and Antarctic Peninsula ice sheets increased significantly. We also see that the mass change along coastal areas of the East Antarctic ice sheet (like Queen Maud Land) increased. The central part of the East Antarctic ice sheet does not exhibit significant mass changes over the period from April 2002 and June 2017. Coastal regions between Dronning Maud Land and Enderby Land $\left(20^{\circ} \mathrm{W}-60^{\circ} \mathrm{E}\right)$ exhibited a minor mass gain, while a slight mass loss was detected between Wilkes Land and Victoria Land $\left(110^{\circ} \mathrm{E}-160^{\circ} \mathrm{E}\right)$. The Antarctic ice sheet gained mass through snowfall, while lost mass at its margins through submarine melting and iceberg calving. These losses occurred primarily within ice shelves and floating ice sheet. Almost the entire ice sheet in West Antarctica experienced a clear mass loss over the investigated period. The negative mass-change pattern 

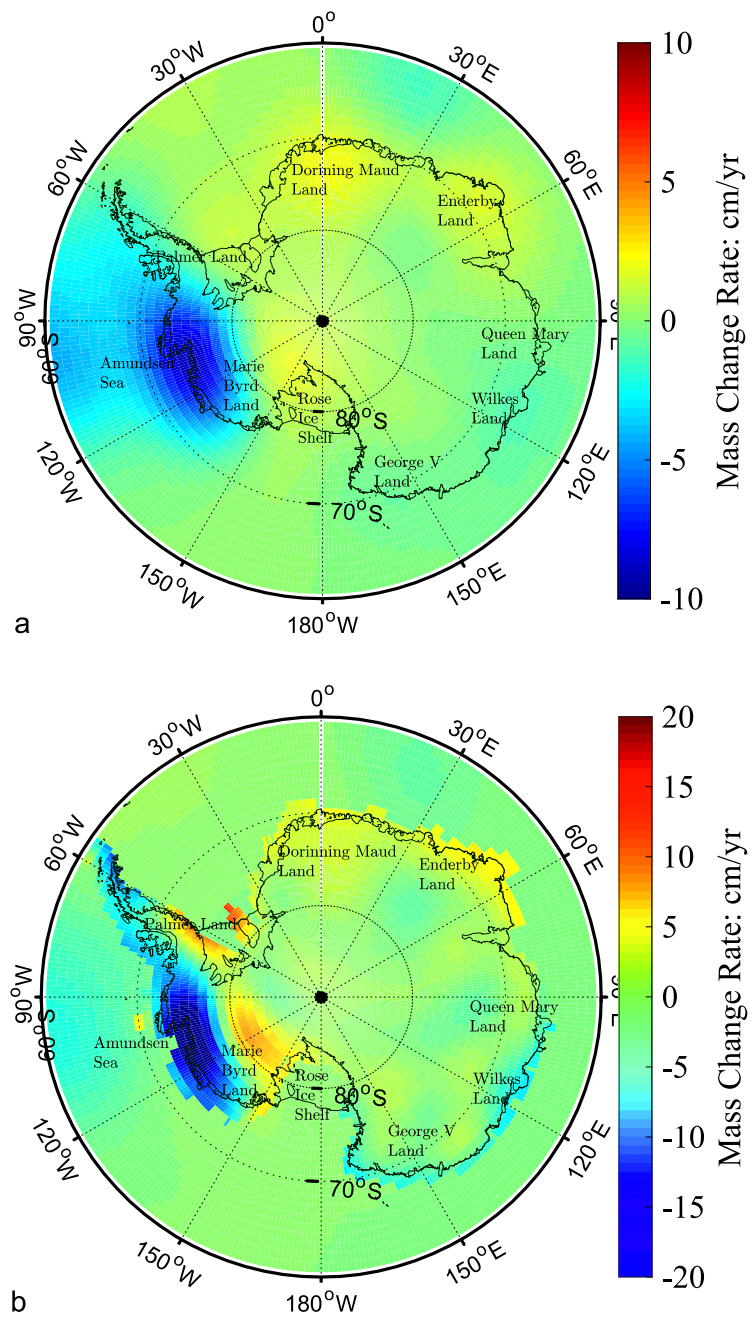

Fig. 3. The average annual rates $(\mathrm{mm} / \mathrm{yr})$ of equivalent water thickness between April 2002 and June 2017 derived from: (a) processing the GRACE monthly solutions, and (b) the forward modeling reconstructed estimate. The GIA effect was corrected for according to $A$ et al. (2013).

spreads from the tip of the Antarctic Peninsula up to the coast of Marie Byrd Land. The most rapid decrease of the Antarctic ice sheet occurred along the coast of the Amundsen Sea with substantial thinning of adjoining ice shelves and along the Antarctic Peninsula after ice-shelf disintegration 
events. The estimated rate after correcting for the leakage effect has a consistent trend and seasonal periodic variation with the estimated rate directly from GRACE data. The results are plotted in Fig. 4. Both solutions shown in Fig. 3 exhibit a secular rate of decreasing mass changes (between April 2002 and June 2017). According to a reconstructed trend (obtained after applying the forward modelling), the total ice/snow budget over this period decreased at a rate of $-162.91 \pm 5.09 \mathrm{Gt} / \mathrm{yr}$, attributing to the global sea level rise by $0.45 \mathrm{~mm} / \mathrm{yr}$. The GIA effect of $-98.12 \mathrm{Gt} / \mathrm{yr}$ was taken from A et al. (2013). A downtrend estimated directly from GRACE data (without applying the forward modelling) was at a rate of $-137.87 \pm 4.42 \mathrm{Gt} / \mathrm{yr}$. The time series of the Antarctic ice sheet change shows a clear seasonal signal that is superimposed over a linear trend (cf. Fig. 4).

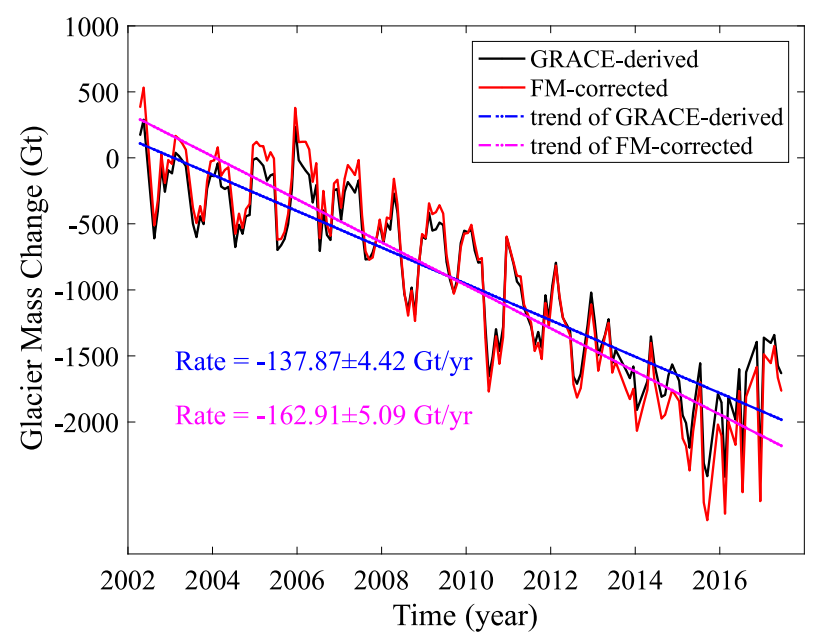

Fig. 4. Time series of mass variations of the Antarctic ice sheet between April 2002 and June 2017. Black lines represent direct estimates from GRACE monthly solutions, and red lines show reconstructed mass variations by using the forward modelling technique. Blue-dotted lines present a linear rate of direct GRACE estimates, and red-dotted lines show a linear rate of reconstructed mass variations. The GIA effect was corrected for according to $A$ et al. (2013).

Mass changes on the Antarctic ice sheet exhibited significant spatial heterogeneities (Fig. 3) that reflect a unique topography and climatic conditions of its different regions. To illustrate this, we plotted mass variations individually for each drainage area (Fig. 5). For the Antarctic ice sheet, the 

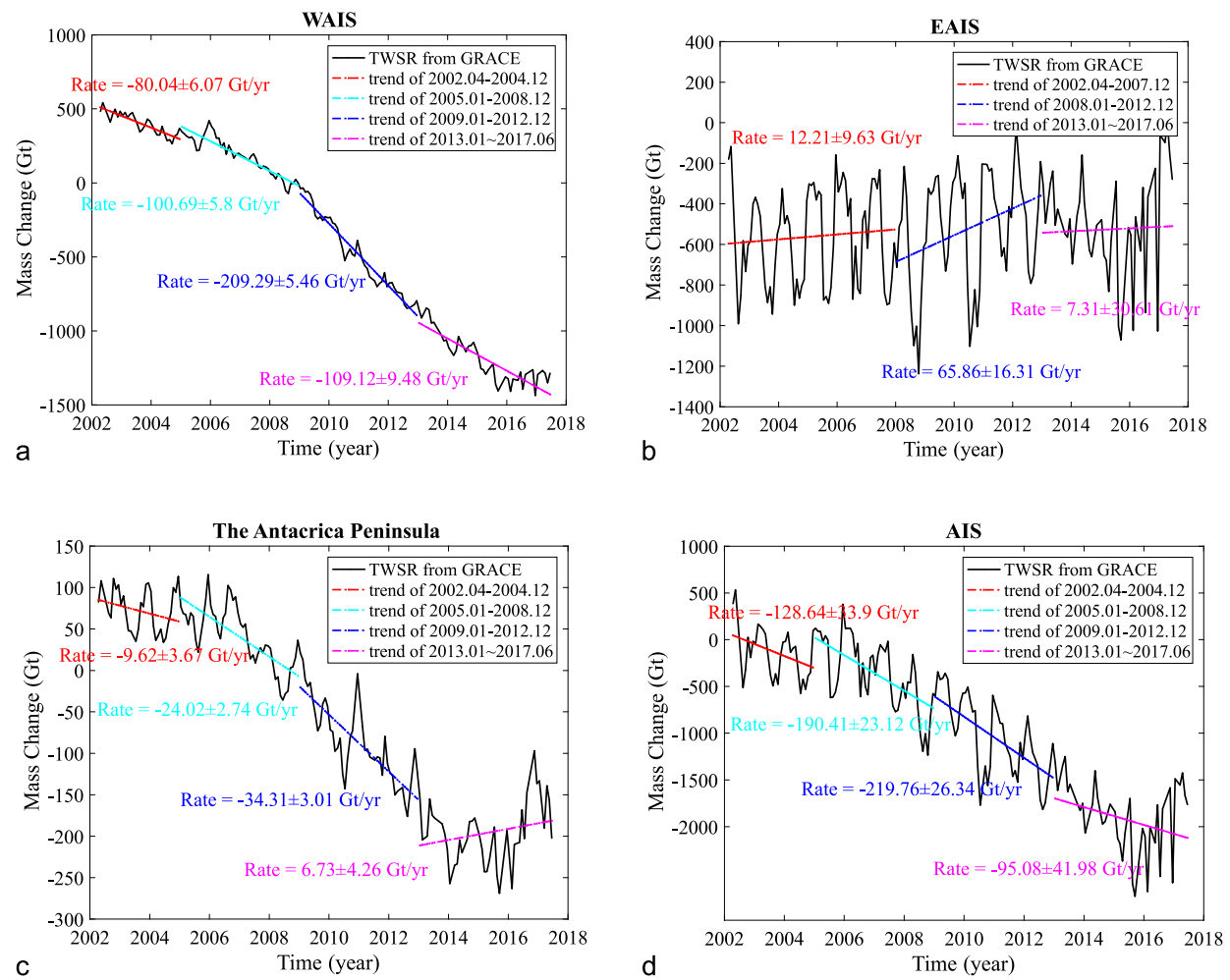

Fig. 5. The time series of total mass balance of: (a) the West Antarctic ice sheet, (b) the East Antarctic ice sheet, (c) the Antarctic Peninsula ice sheet, and (d) the whole Antarctic ice sheet. The GIA effect was corrected for according to $A$ et al. (2013).

time series during the whole investigated period was separated into four distinctive events. The first period between March 2003 and December 2004 is characterized by the mass loss at a rate of $-128.64 \mathrm{Gt} / \mathrm{yr}$. After 2005 , the mass loss reached a rate of $-190.41 \mathrm{Gt} / \mathrm{yr}$, and further accelerated after January 2009 until December 2012 at a rate up to $-219.76 \mathrm{Gt} / \mathrm{yr}$. After January 2013 until June 2017, the mass loss was at a rate of $-95.08 \mathrm{Gt} / \mathrm{yr}$

Compared to temporal changes of the total mass volume of the Antarctic ice sheet, we see quite different patterns for individual drainage areas. The West Antarctic ice sheet is characterized by mass loss over the whole investigated period. The fastest mass loss at a rate of $209.29 \mathrm{Gt} / \mathrm{yr}$ occurred between January 2009 and December 2012. Prior to January 2009, 
the detected mass loss was clearly lower. After January 2013, the mass loss again slowed down in the West Antarctica. Most of this mass loss happen in the Amundsen Sea region. These results are consistent with findings by Dutrieux et al. (2014). They detected a significant drop in seawater temperature of the Amundsen Sea between 2012 and 2013. Our results are also highly consistent with observations made by Mouginot et al. (2014) using InSAR data. We see a similar decreasing trend for the Antarctic Peninsula ice sheet, except for the last period from January 2013 until June 2017 when we observe a slight mass increase at a rate of $6.73 \mathrm{Gt} / \mathrm{yr}$. In contrast, the mass balance of the East Antarctic ice sheet is relatively stable with only a minor increase, except for the period of a relatively fast mass increase between January 2008 and December 2012 at a rate of 65.86 Gt/yr. Two exceptionally large accumulation events took place in Dronning Maud Land in 2009 and 2011 (Boening et al., 2012; Lenaerts et al., 2013).

\subsection{Elevation changes from ICESat}

In Fig. 6, we present the first maps of ice elevations and its changes for the entire Antarctic ice sheet derived from ICESat data acquired during the period from March 2003 to October 2009. We used in total 200 million areas in Antarctica to derive the elevation change map that successfully reproduced large-scale patterns of ice sheet changes. The most prominent changes in ice elevations are associated with a strong dynamical thinning in the Amundsen Sea Embayment. This phenomenon has been confirmed to be caused by the rapid flow of glaciers and their tributaries. Crosson and Dotson ice shelves, situated near the Amundsen Sea, have been infused by many small independent glaciers that also experienced a dynamic thinning explained by ocean currents (cf. Pritchard et al., 2009). A dynamic thinning was also observed at Totten Glacier (that is part of the East Antarctic ice sheet) and some large glaciers along the Antarctic Peninsula. In Dronning Maud Land (in East Antarctica), on the other hand, we detected an extended area of dynamic thickening of up to $0.30 \mathrm{~m} / \mathrm{yr}$. The dynamic thickening was detected also inland but at lower rates approximately within 0.1 to $0.2 \mathrm{~m} / \mathrm{yr}$. Most of central part of the East Antarctic ice sheet is nearly stable, without exhibiting any significant changes in ice elevations. This finding agrees with our results of mass changes obtained from processing GRACE data. 
The largest decrease in ice elevations was inferred over the terminus of Smith Glacier (part of the West Antarctic ice sheet) with a maximum surface lowering at a rate of $-6.4 \mathrm{~m} / \mathrm{yr}$. Another large decrease was found over the Wilkes Land (part of the East Antarctic ice sheet) at a rate of $-0.8 \mathrm{~m} / \mathrm{yr}$. Elsewhere in East Antarctica, we detected a clear growth of the ice sheet near the Enderby Land, Ellsworth Land and Macrobertson Land (near the Amer Ice sheet) that is likely attributed to ocean currents.

We see apparent similarities between spatial patterns of the total mass changes from GRACE (Fig. 3b) and elevation changes from ICESat (Fig. 6b). Both, GRACE and ICESat results revealed the largest mass and elevation changes in the Amundsen Sea region. When integrated over whole Antarctica, the average elevation changes derived from the ICESat (after applying also the GIA correction) correspond to a total loss of ice volume of $-155.6 \mathrm{~km}^{3}$ (between March 2003 and October 2009). Most of this mass loss $\left(-139.7 \mathrm{~km}^{3}\right)$ happened in West Antarctica, while much less $\left(-37.1 \mathrm{~km}^{3}\right)$ in the Antarctic Peninsula. East Antarctica exhibited a slight mass increase $\left(21.2 \mathrm{~km}^{3}\right)$.
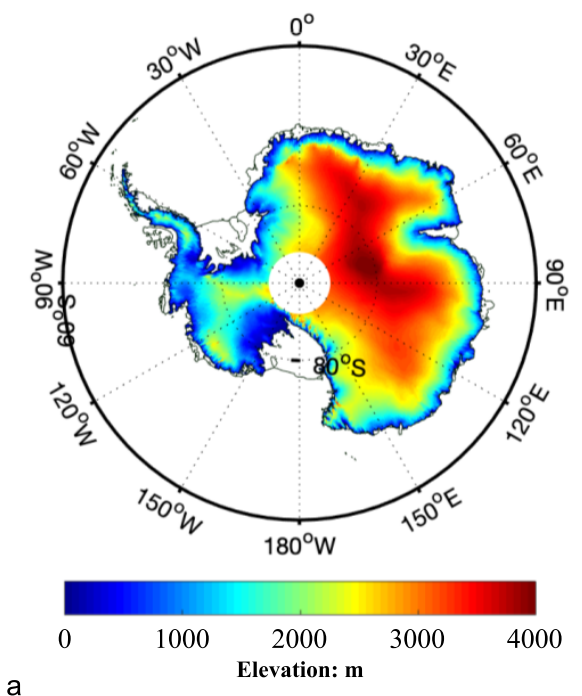
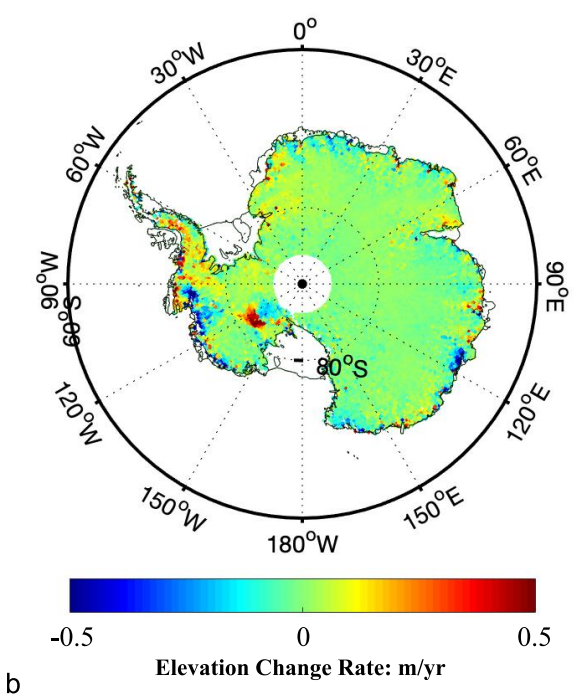

b

Fig. 6. Maps of: (a) the ice elevation (m) and (b) its changes (m/yr) in Antarctica over the period from March 2003 to October 2009 derived from ICESat data. 


\subsection{Displacement from GNSS and GRACE}

The vertical displacement rates at 44 Antarctic GNSS stations over the period from 1992 to 2018 provided by the Jet Propulsion Laboratory (https : //sideshow.jpl.nasa.gov/post/series.html) are shown in Fig. 7. In Fig. 8, we plotted the vertrical displacements obained from GRACE data

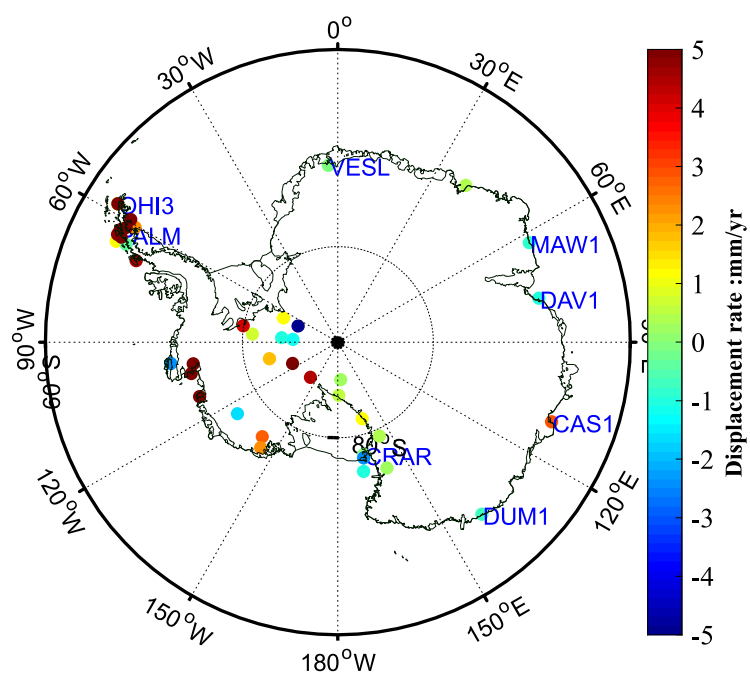

Fig. 7. The vertical displacement rates at 44 GNSS stations in Antrarctica over the period from 1992 to 2018.

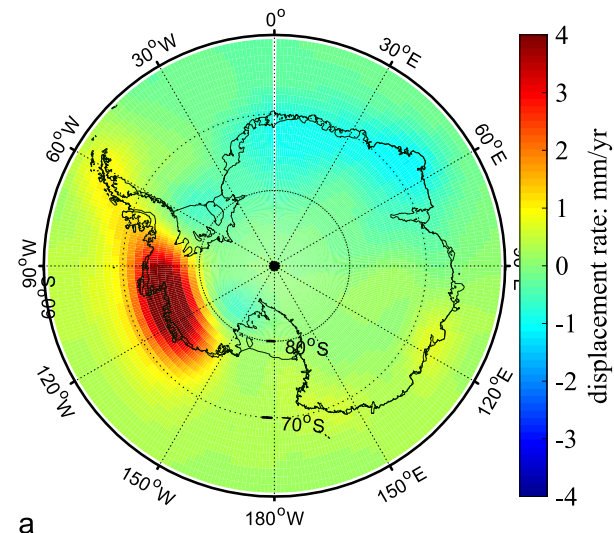

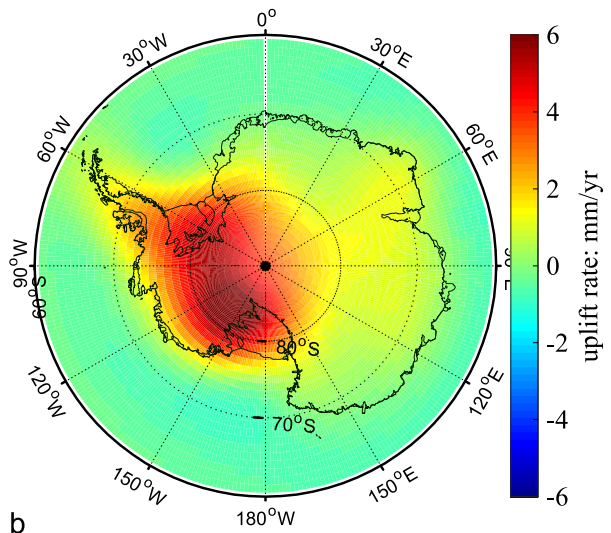

b

(a) GRACE, and (b) GIA model (A et al., 2013). 
and accoding to GIA model (A et al., 2013). We note that all these GNSS stations are stabilized to the bedrock. We see a relatively good spatial consistency between the vertical displacement rates from GRACE (Fig. 8a) and GNSS observations (Fig. 7) when compared with the vertical load displacement rates from the GIA model (A et al., 2013) that was derived from the ice-load history and the viscosity profiles. These findings indicate that most of the long-term changes in vertical loads, which were estimated from GNSS and GRACE, are due to GIA. The largest vertical changes are mainly concentrated in the Ronne Ice Shelf, the Ross ice shelf, Enderby Land, Amery Ice Shelf and Princess Elizabeth Land. To have consistency between the time span of records at 44 GNSS sites and GRACE time coverage, we selected only 8 stations (those which have data over the whole period as GRACE from April 2002 until June 2017) to conduct the comparison of vertical displacement rates from GNSS and GRACE. The annual signals from GNSS and GRACE are plotted in Fig. 9. For most of sites, the GRACE signal appears to be in phase and have the same amplitude as GPS signal. A particularly good agreement is seen at sites of CAS1, CRAR, DAV1 and MAW1. This shows that the ice mass changes close to these sites can (to a large extent) explain the surface deformations, because the vertical displacements from GNSS include the loading deformation due to the mass changes as well as the vertical crustal motions. There are also sites where the GNSS and GRACE estimates differ significantly in amplitude and phase, like OHI3 and PALM sites instated in the Antarctica Peninsula.

\section{Discussion}

Large uncertainties in GRACE and ICESat estimates are mainly due to the GIA effect (cf. Gunter el al., 2009; Ivins et al., 2013). The knowledge of GIA with a high accuracy is thus indispensable for studying changes in total mass budget of the Antarctic ice sheet. Moreover, the estimates of ice elevation changes from ICESat are affected by an unknown time-varying compaction effect of snow and firn ice that complicates the conversion of elevation-tomass changes. Whether using the density of ice $\left(917 \mathrm{~kg} / \mathrm{m}^{3}\right)$ or the surface mass density model, the results are exactly correct only in an ideal condition that obviously deviates from the actual situation in many regions of 

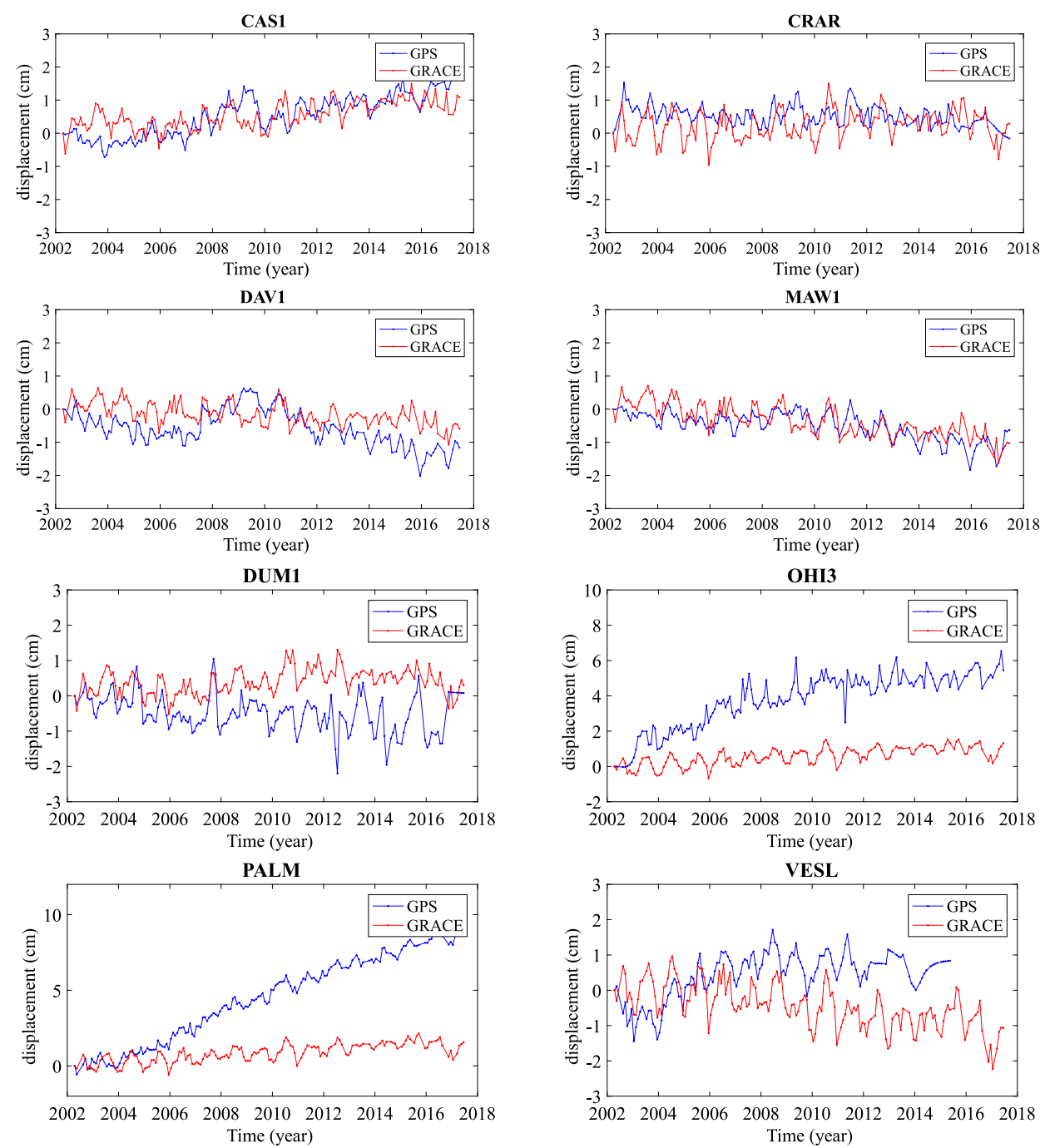

Fig. 9. The vertical displacments at 8 GNSS sites in Antarctica from GNSS and GRACE.

Antarctica, especially along ice sheet margins where mass fluctuations are quite large. Areas with large uncertainties are generally concentrated in areas with high ice flow rates. The more complex the ice sheet elevation changes in regions with a higher ice flow velocity (mostly coastal areas), the 
greater the uncertainties of ICESat results. Furthermore, regions with a high ice flow velocity are characterized by typically larger mass changes and consequently affected more by a leakage effect that substantially influences GRACE estimates.

The discrepancies between the load displacements monitored by GNSS and GRACE might be explained by the fact that surface displacements at these GNSS sites are also affected by the thermo-elastic deformations associated with surface temperature changes in addition to the influence of surface mass redistribution (Tan et al., 2016; 2017). While the GRACE observations are only sensitive to mass changes, they are not affected by the surface temperature. Another possible reason for these differences is a limited spatial resolution of GRACE. Moreover, GRACE estimates represent regional averages, while the GNSS estimates reflect vertical motions at particular locations.

\section{Summary and Conclusions}

We have investigated the ice mass changes, the ice elevation changes and vertical displacements in Antarctica from processing GRACE and ICESat data. In addition, we analyzed the vertical displacement from GNSS data and GIA model.

According to our results, the total mass change of the Antarctic ice sheet was at a rate of $-162.91 \pm 5.09 \mathrm{Gt} / \mathrm{yr}$ during the period from April 2002 to June 2017. Most of these changes are attributed to the ice mass loss of the West Antarctic ice sheet (at a rate of $-143.11 \pm 2.24 \mathrm{Gt} / \mathrm{yr}$ ) and the Antarctic Peninsula ice sheet (at a rate of $-24.31 \pm 0.71 \mathrm{Gt} / \mathrm{yr}$ ). In contrast, we detected a small ice mass increase (at a rate of $5.29 \pm 3.54 \mathrm{Gt} / \mathrm{yr}$ ) of the East Antarctic ice sheet over the investigated period. These significant spatial heterogeneities (Fig. 3) in changes of the total mass balance reflect a unique topography and climatic conditions of different regions at this continent. Interestingly, the most significant spatial factor is not necessary the contrast between coastal and inland areas that mainly controls the total mass budget in Greenland. Instead, in Antarctica the contrast between mass changes in West and East Antarctica are also significant. The fastest ice mass loss was detected in Amundsen Sea Embayment (i.e. Marie Byrd Land) at a rate up 
to $-10 \mathrm{~cm} / \mathrm{yr}$. Among remarkable spatial variations in the ice mass changes, we detected also large temporal variations in different regions during the investigated period of fifteen years. Overall, temporal variations of ice mass changes over the entire continent of Antarctica could be characterized by an accelerating mass loss from March 2003 until December 2012, followed by slowing trend after January 2013 until June 2017.

The large ice mass loss detected by GRACE in the Amundsen Sea Embayment was confirmed from ICESat data, with the localized extreme decrease in ice elevations at a rate of $-6.4 \mathrm{~m} / \mathrm{yr}$ inferred over the terminus of Smith Glacier. This significant dynamic thinning was explained by ocean currents. In Dronning Maud Land, the ICESat estimates indicate a relatively significant dynamic thickening at a rate of $0.30 \mathrm{~m} / \mathrm{yr}$.

The vertical load displacement rates estimated by GRACE and GNSS are in good agreement with the GIA model developed by $A$ et al. (2013) based on the ICE5G ice-load history, the VM2 viscosity profile and the same PREM elastic structure. For most sites, the GRACE signal appears to be in phase and have the same amplitude as those detected from GNSS, but large discrepancies were also found. These discrepancies might be due to the fact that GNSS estimates are also affected by the thermo-elastic deformations associated with surface temperature, while GRACE detects only mass changes.

Acknowledgements. This research was funded by the Hong Kong Research Grants Council, Project 1-ZE8F: Remote-sensing data for studying Earth's and planetary inner structure.

\section{References}

A G., Wahr J., Zhong S., 2013: Computations of the viscoelastic response of a 3-D compressible Earth to surface loading: an application to Glacial Isostatic Adjustment in Antarctica and Canada. Geophys. J. Int., 192, 2, 557-572, doi: 10.1093/gji/ ggs030.

Boening C., Lebsock M., Landerer F., Stephens G., 2012: Snowfall-driven mass change on the East Antarctic ice sheet. Geophys. Res. Lett., 39, 21, L21501, doi: 10.1029/20 12 GL053316.

Chen J. L., Wilson C. R., Blankenship D., Tapley B. D., 2009: Accelerated Antarctic ice loss from satellite gravity measurements. Nat. Geosci., 2, 859-862, doi: 10.1038/ ngeo694. 
Chen J. L., Wilson C. R., Blankenship D. D., Tapley B. D., 2006: Antarctic mass rates from GRACE. Geophys. Res. Lett., 33, 11, L11502, doi : 10.1029/2006GL026369.

Dutrieux P., De Rydt J., Jenkins A., Holland P. R., Ha H. K., Lee S. H., Steig E. J., Ding Q., Abrahamsen E. P., Schröder M., 2014: Strong sensitivity of Pine Island ice-shelf melting to climatic variability. Science, 343, 6167, 174-178, doi: 10.1126/science .1244341 .

Farrell W. E., 1972: Deformation of the Earth by surface loads. Rev. Geophys., 10, 3, 761-797, doi: 10.1029/RG010i003p00761.

Gunter B., Urban T., Riva R., Helsen M., Harpold R., Poole S., Nagel P., Schutz B., Tapley B., 2009: A comparison of coincident GRACE and ICESat data over Antarctica. J. Geod., 83, 11, 1051-1060, doi: 10.1007/s00190-009-0323-4.

Hanna E., Navarro F. J., Pattyn F., Domingues C. M., Fettweis X., Ivins E. R., Nicholls R. J., Ritz C., Smith B., Tulaczyk S., Whitehouse P. L., Zwally H. J., 2013: Ice-sheet mass balance and climate change. Nature, 498, 7452, 51-59, doi: 10.1038/nature 12238.

Ivins E. R., James T. S., Wahr J., Schrama E. J. O., Landerer F. W., Simon K. M., 2013: Antarctic contribution to sea level rise observed by GRACE with improved GIA correction. J. Geophys. Res. Solid Earth, 118, 6, 3126-3141, doi: 10.1002/jgrb.50208.

Jacob T., Wahr J., Pfeffer W. T., Swenson S., 2012: Recent contributions of glaciers and ice caps to sea level rise. Nature, 482, 7386, 514-518, doi: 10.1038/nature10847.

Klees R., Revtova E., Gunter B., Ditmar P., Oudman E., Winsemius H., Savenije H., 2008: Filter design for GRACE gravity models. Geophys. J. Int., 175, 2, 417-432, doi : $10.1111 / \mathrm{j} .1365-246 \mathrm{X} .2008 .03922 . \mathrm{x}$.

Lenaerts J. T. M., van Meijgaard E., van den Broeke M. R., Ligtenberg S. R. M., Horwath M., Isaksson E., 2013: Recent snowfall anomalies in Dronning Maud Land, East Antarctica, in a historical and future climate perspective. Geophys. Res. Lett., 40, 11, 2684-2688, doi: 10.1002/grl.50559.

Mouginot J., Rignot E., Scheuchl B., 2014: Sustained increase in ice discharge from the Amundsen Sea Embayment, West Antarctica, from 1973 to 2013. Geophys. Res. Lett., 41, 5, 1576-1584, doi: 10.1002/2013GL059069.

Pritchard H. D., Arthern R. J., Vaughan D. G., Edwards L. A., 2009: Extensive dynamic thinning on the margins of the Greenland and Antarctic ice sheets. Nature, 461, 7266, 971-975, doi: 10.1038/nature08471.

Shepherd A., Wingham D., 2007: Recent sea-level contributions of the Antarctic and Greenland ice sheets. Science, 315, 5818, 1529-32, doi: 10.1126/science.1136776.

Tan W., Dong D., Chen J., Wu B., 2016: Analysis of systematic differences from GPSmeasured and GRACE-modeled deformation in Central Valley, California. Adv. Space Res., 57, 1, 19-29, doi: 10.1016/j.asr.2015.08.034.

Tan W., Xu X., Dong D., Chen J., Wu B., 2017: Thermoelastic Seasonal Deformation in Chinese Mainland. Acta Geod. et Cartogr. Sin., 46, 9, 1080-1087, doi: 10.11947/j . AGCS . 2017.20160628.

Tang J., Cheng H., Liu L., 2012: Using nonlinear programming to correct leakage and estimate mass change from GRACE observation and its application to Antarctica. J. Geophys. Res. Solid Earth, 117, B11, B11410, doi : 10.1029/2012JB009480. 
Van Wessem J. M., Reijmer C. H., Morlighem M., Mouginot J., Rignot E., Medley B., Joughin I., Wouters B., Depoorter M. A., Bamber J. L., Lenaerts J. T. M., Van De Berg W. J., Van Den Broeke M. R., Van Meijgaard E., 2014: Improved representation of East Antarctic surface mass balance in a regional atmospheric climate model. J. Glaciol., 60, 222, 761-770, doi : 10.3189/2014JoG14J051.

Velicogna I., 2009: Increasing rates of ice mass loss from the Greenland and Antarctic ice sheets revealed by GRACE. Geophys. Res. Lett., 36, 19, L19503, doi : 10.1029/2009 GL040222.

Velicogna I., Sutterley T. C., van den Broeke M. R., 2014: Regional acceleration in ice mass loss from Greenland and Antarctica using GRACE time-variable gravity data. Geophys. Res. Lett., 41, 22, 8130-8137, doi : 10.1002/2014GL061052.

Velicogna I., Wahr J., 2006: Measurements of time-variable gravity show mass loss in Antarctica. Science, 311, 5768, 1754-1756, doi: 10.1126/science.1123785.

Velicogna I., Wahr J., 2013: Time-variable gravity observations of ice sheet mass balance: Precision and limitations of the GRACE satellite data. Geophys. Res. Lett., 40, 12, 3055-3063, doi : 10.1002/grl.50527.

Wahr J., Swenson S., Velicogna I., 2006: Accuracy of GRACE mass estimates. Geophys. Res. Lett., 33, 6, L06401, doi: 10.1029/2005GL025305.

Wahr J., Molenaar M., Bryan F., 1998: Time variability of the Earth's gravity field: Hydrological and oceanic effects and their possible detection using GRACE. J. Geophys. Res., Solid Earth, 103, B12, 30205-30229, doi: 10.1029/98JB02844.

Zammit-Mangion A., Rougier J., Schön N., Lindgren F., Bamber J., 2015: Multivariate spatio-temporal modelling for assessing Antarctica's present-day contribution to sea-level rise. Environmetrics, 26, 3, 159-177, doi: 10.1002/env. 2323.

Zwally H. J., Giovinetto M. B., Li J., Cornejo H. G., Beckley M. A., Brenner A. C., Saba J. L., Yi D., 2005: Mass changes of the Greenland and Antarctic ice sheets and shelves and contributions to sea-level rise: 1992-2002. J. Glaciol., 51, 175, 509-527, doi : 10.3189/172756505781829007. 